\title{
Design of Vibration Frequency Method with Fine-Tuned Factor for Fault Detection of Three Phase Induction Motor
}

\author{
Thomas Amanuel ${ }^{1}$, Amanuel Ghirmay ${ }^{2}$, Huruy Ghebremeskel ${ }^{2}$, \\ Robel Ghebrehiwet ${ }^{2}$, Weldekidan Bahlibi ${ }^{2}$ \\ ${ }^{1}$ Graduate Assistant, \\ Mainefhi College of Engineering, \\ Asmara, Ministry of Education, \\ Eritrea. \\ tomiasli123@gmail.com
}

${ }^{2}$ Mainefhi College of Engineering,

Asmara,

Eritrea.

Abstract- This research article focuses on industrial applications to demonstrate the characterization of current and vibration analysis to diagnose the induction motor drive problems. Generally, the induction motor faults are detected by monitoring the current and proposed finetuned vibration frequency method. The stator short circuit fault, broken rotor bar fault, air gap eccentricity, and bearing fault are the common faults that occur in an induction motor. The detection process of the proposed method is based on sidebands around the supply frequency in the stator current signal and vibration. Moreover, it is very challenging to diagnose the problem that occur due to the complex electromagnetic and mechanical characteristics of an induction motor with vibration measures. The design of an accurate model to measure vibration and stator current is analyzed in this research article. The proposed method is showing how efficiently the root cause of the problem can be diagnosed by using the combination of current and vibration monitoring method. The proposed model is developed for induction motor and its circuit environment in MATLAB is verified to perform an accurate detection and diagnosis of motor fault parameters. All stator faults are turned to turn fault; further, the rotor-broken bar and eccentricity are structured in each test. The output response (torque and stator current) is simulated by using a modified winding procedure (MWP) approach by tuning the winding geometrical parameter. The proposed model in MATLAB Simulink environment is highly symmetrical, which can easily 
Journal of Innovative Image Processing (JIIP) (2021)

Vol.03/ No. 01

Pages: 52-65

https://www.irojournals.com/iroiip/

DOI: https://doi.org/10.36548/jiip.2021.1.005

detect the signal component in fault frequencies that occur due to a slight variation and improper motor installation. Finally, this research article compares the other existing methods with proposed method.

Keywords: Induction Motor Faults, Vibration Frequency Method

\section{INTRODUCTION}

Recently, condition monitoring is used to achieve the performance of industry machinery that decreases the significant resultant harm and optimizes the life span of different electrical machinery types [1]. These are lowering the inventories of the spare accessories and unwanted maintenance cost due to unfortunate breakdown.

The early detection of faults in machinery and its diagnosis in an industry with the least maintenance procedure becomes shutdown. Moreover, the production loss is improving based on frequent breakdown of machineries [2]. This continuous monitoring must be a highly effective procedure and also it provides a warning at the earlier stage of breakdown problems. This monitoring procedure retrieves the information of the machine with raw data to articulate well defined between the motor original signal at normal condition and fault state condition [3]. The classifying condition of the induction motor evaluated with the corresponding frequency of fault occurrences from the signal remains as a challenging work [4]. The majority of the manufacturers and users trust in simple continuous monitoring procedures with labor costs. The induction motor protection is ensuring the reliable system function by estimating over current and voltages [5]. The complicated application of induction motor is associated with modern industrial application recently. Although, the human-machine interface is essential for online detection requirements, which diagnosed the faults in a machine before the occurrence of hazards and process disruption [6].

Different methods are developed to detect the different faults of induction motor at various stages under machine conditions such as current, voltage, temperature, vibration of the machine, and so on [7]. This monitoring technique of induction motor is very essential for safety and economic considerations. The fixed time interval maintenance is a very traditional method to detect the faults in induction motor, which provides good results. Recently, technology makes

ISSN: 2582-4252 (online) 
Journal of Innovative Image Processing (JIIP) (2021)

Vol.03/ No. 01

Pages: 52-65

https://www.irojournals.com/iroiip/

DOI: https://doi.org/10.36548/jiip.2021.1.005

predictive maintenance through many techniques such as artificial intelligence (AI) [8]. Figure 1 shows the general classification of induction motor faults.

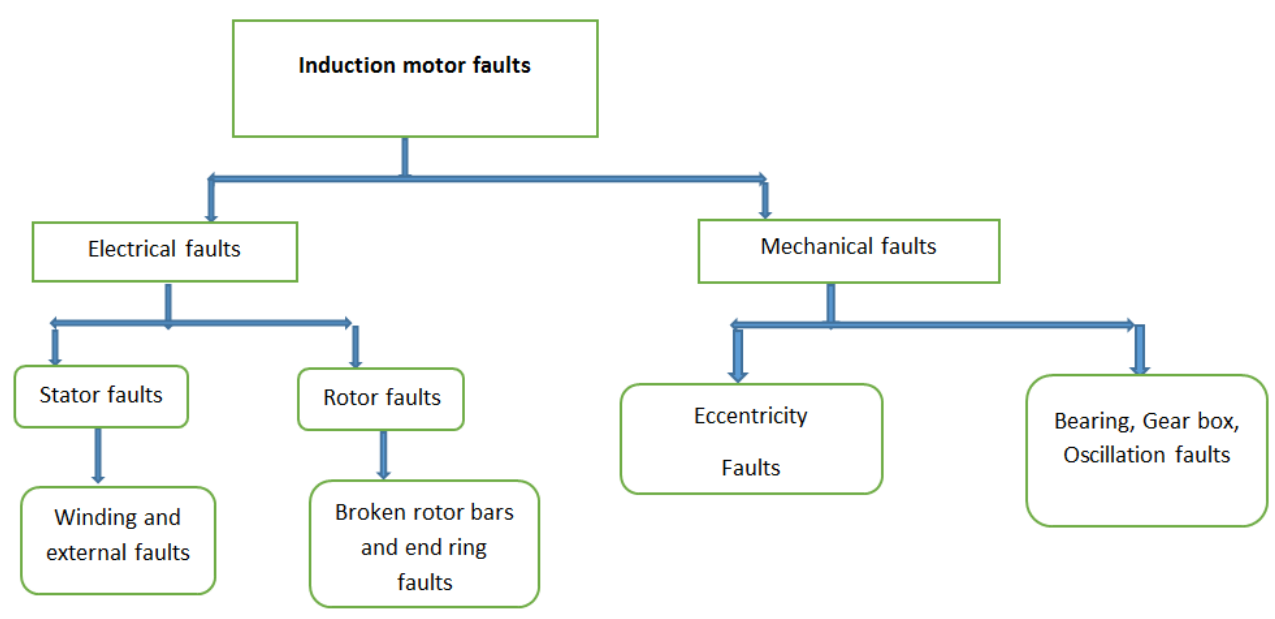

Figure 1 Classification of Induction motor faults

In earlier days, continuous supervision with human presence is an appropriate procedure to identify faults in any machine. The monitoring methodologies can encompass the logical progression for the diagnosis process in automation [9]. Recently, several soft computing techniques are introduced for performing the automated diagnostic process. Table 1 shows the percentage of fault occurrence possibilities for induction motors.

Table 1 Fault occurrence possibility on induction motor [14]

\begin{tabular}{|c|c|c|c|c|}
\hline Studied by & $\begin{array}{c}\text { Bearing } \\
\text { Fault }(\%)\end{array}$ & $\begin{array}{c}\text { Stator } \\
\text { Faults }(\%)\end{array}$ & $(\%)$ Rotor fault & Others $(\%)$ \\
\hline IEEE & 42 & 28 & 8 & 22 \\
\hline EPRI & 41 & 36 & 9 & 14 \\
\hline
\end{tabular}

The vibration measures provide the accuracy and spontaneous diagnosis tool to diagnose the fault in an induction motor. This research article provides the systematic review of fault detection and diagnosis of squirrel cage rotor type induction motor with vibrational frequency analysis for both the conditions (stationary and non-stationary) [10]. Besides, MATLAB is used to perform Simulink in order to view the vibrational signal spectrum.

ISSN: 2582-4252 (online) 
Journal of Innovative Image Processing (JIIP) (2021)

Vol.03/ No. 01

Pages: 52-65

https://www.irojournals.com/iroiip/

DOI: https://doi.org/10.36548/jiip.2021.1.005

\section{ORGANIZATION OF THE RESEARCH}

The structure of the research article is organized as follows; Section 3 gives related existing research work for induction motor fault detection. Section 4 describes the proposed model to detect faults in an induction motor. Section 5 discusses the obtained results from MATLAB and finally, section 6 presents the conclusion and future enhancement of this research article.

\section{PRELIMINARIES}

Kato et al proposes the direct detection technique with asymmetry admittance components for the diagnosis of stator winding faults in an induction motor. The asymmetry admittance components are considered for faulty situations under various load conditions by using simulating procedures. The amplitude and phase of positive and negative sequence voltages and values are derived from the current park vectors. The computation of asymmetry admittance is repeating with many test steps for an induction motor [11].

Trabelsi et al present an investigation of insulated gate bipolar transistors (IGBTs) opencircuit for fault detection and diagnosis in voltage source fed inverter 3-phase induction motors. The proposed approach is based on the combination of the measurement of inverter pole voltage and switching method. The signals are collected to detect the fault identification with multiple open circuits out of many switching circuits. The time delays that turn ON or OFF the process are compensating the switching pattern to minimize the false diagnosis indication [12].

Aktas, $\mathrm{M}$ has developed the IGBT-based technique, which is used to detect the fault in an open circuit based on direct torque control of induction motor. The discrete wavelet transform (DWT) with symlet2 wavelets are utilized in the fault identification process based on the signal matching procedure [13]. The next research work proposes a park vector modulus (PVM) approach to discriminate stator winding inter-turn fault scenarios. The fluctuation voltage supply exhibits the same type of current pattern. The digital signal processing method with fast Fourier transform (FFT) has been used to determine the power spectral density, which is used for estimating the inter-turn fault [14]. Khan et al introduces the multi DWT methods to possess the behavior of fault identification and classification in an induction motor. The DWT coefficients were considered for the classification process with the occurrence of various faults in the induction motor and it is also used to differentiate the faults [15]. Soualhi et al proposed a new methodology for fault detection 
Journal of Innovative Image Processing (JIIP) (2021)

Vol.03/ No. 01

Pages: 52-65

https://www.irojournals.com/iroiip/

DOI: https://doi.org/10.36548/jiip.2021.1.005

and diagnosis of induction motors by using the signal-based method. This signal processing-based technique is combined with an artificial ant clustering process for the detection of faults in squirrel cage induction motor of $5.5 \mathrm{~kW}$. The rotor has monitored the bearing failure at different load levels [16]. Amaral,T.G et al presented the technique, which is comprised of an analysis of input current park's vector and phase currents to 3 phase system. This proposed algorithm is used to identify the motor stator fault. This pattern recognition method is combined with the statistic moment method to diagnose the fault in an induction motor. The Simulink has been executed with good efficiency [17].

Eltabach, $\mathrm{M}$ et al discuss the comparative evaluation of various methods of non-invasive diagnosis for any mechanical faults in the motor. Any noise signals have occurred in voltage and current signals of the stator of the motor, the fault identification remains as a very challenging task. The signals are also used to compute the instantaneous power signal from voltage and current signals. The other procedure part of vector approach method is investigated here. In addition to that, the signals are simulated with the waveform by using power spectral density transformation. These signal frequencies are used to investigate the noise immunity of the diagnosis procedure that enables various grouping [18]. Chetwani et al describe the practicability of online monitoring for fault detection at various loads, where it will be evaluated with old motors by severe damage. This monitoring of the current and voltage in a machine, which is normally operated by analyzing the same in the frequency domain for detecting the faults. This proposed method is used to detect various faults such as damage in rotor cage of induction motor. The bearing faults, eccentricity faults, stator turn-to-turn short circuit is monitoring and detecting by stator current variation. Different faults exist in an induction motor are simulating with MATLAB and also they are identified in the online monitoring of current in the frequency domain. The proposed idea is applied for continuously monitoring the motors in the nuclear power plant, which is comprised of the diagnostic tool of motors [19].

\subsection{Problem Statement}

Currently, induction motors are the most widely used machines in industrial, commercial, and domestic applications. This is because they are superior in their reliability, durability, simpler construction, and fairly stable output voltage and torque. Taking all these into account, any failure 
Journal of Innovative Image Processing (JIIP) (2021)

Vol.03/ No. 01

Pages: 52-65

https://www.irojournals.com/iroiip/

DOI: https://doi.org/10.36548/jiip.2021.1.005

in their operation is considered as catastrophic. Thus, it is difficult to have these many advantages, if their operation is faulty. Moreover, it increases the maintenance time. By considering this, it is necessary to provide protection for such machines in order to increase the productivity and minimize the maintenance cost.

\section{METHODOLOGIES}

This research work highlights the bearing fault defects or internal faults by considering any rolling element bearing in a machine as shown in figure 3. A small hole has been assumed in a rotor element that requires to detect the fault and its types artificially by considering the real bearing damages. Practically, various faults and their effects on the machine are distinguished. Figure 2 shows the overview of the proposed practical project setup.

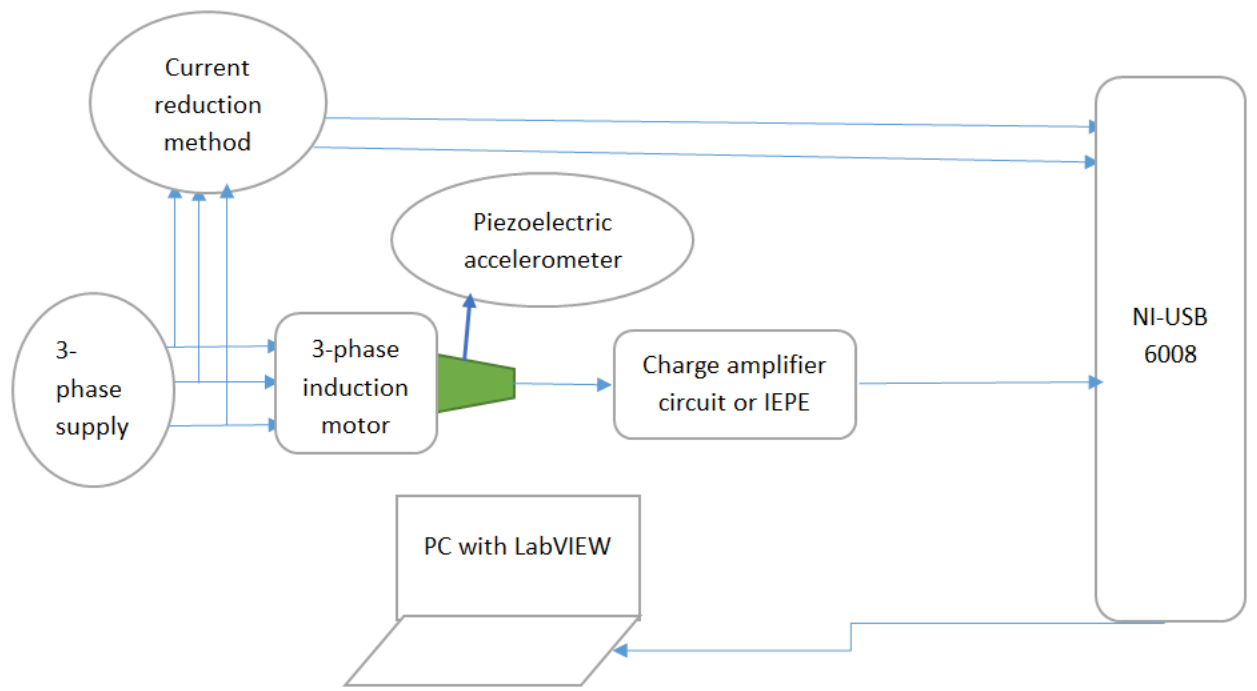

Figure 2 overview of proposed system setup

\subsection{Mathematical Design of Detect the Faults in Machine}

The internal defect in a machine creates the impact of vibration during running a rotor over the surface in the machine can be designed by anomaly's position method. Fundamental characteristic frequency should be designed for each type of bearing fault condition with various load setups [20]. In the outer and inner raceway, the ball is considered for the rotor frequency design. Figure 3 a $\&$ b shows the geometry of rotor element bearing setup and radial rotor movement respectively. This will depend on three various fault types as follows: 
Journal of Innovative Image Processing (JIIP) (2021)

Vol.03/ No. 01

Pages: 52-65

https://www.irojournals.com/iroiip/

DOI: https://doi.org/10.36548/jiip.2021.1.005
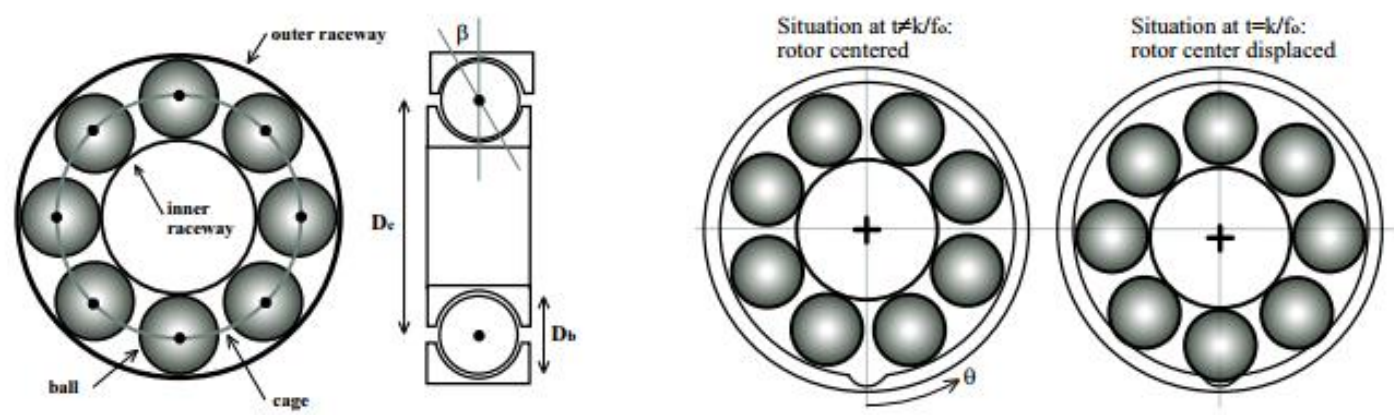

Figure 3 (a) Geometry of Rotor Element Bearing (b) Radial Rotor Movement

Assumption parameters:

Outer raceway: $\quad f_{o}=\frac{N_{b}}{2} f_{r m}\left(1-\left(D_{b} / D_{c}\right) \cos \beta\right)$

Inner raceway: $\quad f_{i}=\frac{N_{b}}{2} f_{r m}\left(1+\left(D_{b} / D_{c}\right) \cos \beta\right)$

Ball: $\quad f_{b}=D_{C} / D_{b} f_{r m}\left(1-\left(D_{b}^{2} / D_{C}^{2}\right) \cos ^{2} \beta\right)$

\subsection{Outer Raceway Defect:}

The outer raceway defect is assumed and located at the angular position $\theta=$ zero in the initial condition. The contact between ball and stator is centered perfectly [21]. In the proposed algorithm, the air gap length $g$ and constant $g_{0}$ are considered in the stator slot pattern. The contacts in the ball are getting a vibration for a small movement of the rotor surface with the reference of stator frame. The air gap length is approximating through relative degree of eccentricity [22] [23] [24]. To frame a model for fault identification through vibration analysis, series of Dirac generalized function will be used [25] [26] [27]. In proposed framework, the vibration frequencies are approximated with statistical method of bearings of 6 to 12 balls inside is given by,

$$
\begin{aligned}
f_{o} & =0.4 N_{b} f_{r m} \\
f_{i} & =0.6 N_{b} f_{r m}
\end{aligned}
$$

The analysis of stator current with air gap length,

$$
g_{o}(\theta, \mathrm{t})=g_{o}\left[\left(1-\mathrm{e}_{o} \cos (\theta) \sum_{\mathrm{k}=-\infty}^{+\infty} \delta\left(\mathrm{t}-k / f_{o}\right)\right]\right.
$$

ISSN: 2582-4252 (online) 
Journal of Innovative Image Processing (JIIP) (2021)

Vol.03/ No. 01

Pages: 52-65

https://www.irojournals.com/iroiip/

DOI: https://doi.org/10.36548/jiip.2021.1.005

\subsection{Inner Raceway Defect:}

The rotor position is changing slightly with time period $t=\frac{k}{f_{i}}$ with angular position of the minimum air gap length. The movement is based on the stator reference frame as rotor rotation at the angular frequency named as $\omega_{r m}$. Radial rotor movement due to an inner bearing race way is showing in figure 4.
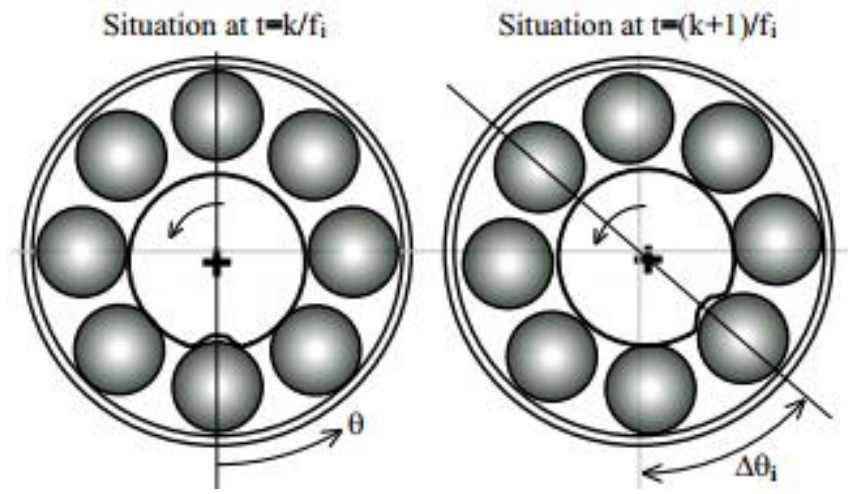

Figure 4 radial rotor movements due to an inner bearing raceway

\subsection{Ball defect:}

This defect is located in a similar way of inner raceway fault based on the air gap length. The angular position of rotor with cage rotational frequency is used to detect the fundamental faults $\omega_{\text {cage }}$ in the ball available in bearings [28] [29]. The fundamental case of frequency is considered as:

$$
\omega_{\text {cage }}=\left[1-\left(D_{b} / D_{c}\right) \cos \beta\right]
$$

This equation is tuned with the modified parameter given as,

\section{Correctness: [Fine-tuned vibration frequency approach]}

$$
\omega_{\text {cage }}=\omega_{r m} / 2\left(1-\left(D_{b} / D_{c}\right) \cos \beta\right)
$$

Where,

$$
\Delta \theta_{i}=\omega_{r m} \Delta \mathrm{t}=\omega_{r m} / f_{i}
$$

This equation output gives accurate detection of bearing fault. Basically, the air flux density, 
Journal of Innovative Image Processing (JIIP) (2021)

Vol.03/ No. 01

Pages: 52-65

https://www.irojournals.com/iroiip/

DOI: https://doi.org/10.36548/jiip.2021.1.005

$$
f_{e c c}=\frac{1}{2 \pi}\left[ \pm \frac{d \Psi(t)}{d t} \pm k \omega_{c}-\omega_{s}\right]
$$

Where,

$$
\begin{aligned}
& \psi(\mathrm{t})=\left\{\begin{array}{l}
0 \\
\omega_{r m} \mathrm{t} \\
\omega_{r m} \mathrm{t}
\end{array}\right. \\
& \text { for an outer race defect } \\
& \text { for an inner race defect } \\
& \text { for a ball defect } \\
& \omega_{c} \text { is cutoff frequency } \\
& \omega_{s} \text { is equivalent to } 2 \pi f_{s}
\end{aligned}
$$

The frequencies obtained by stator current analysis are,

Outer race defect: $\quad \mathrm{f}_{\mathrm{ecc}}=\mathrm{f}_{\mathrm{s}} \pm \mathrm{kf}_{\mathrm{e}}$

Inner race defect: $\quad \mathrm{f}_{\mathrm{ecc}}=\mathrm{f}_{\mathrm{s}} \pm \mathrm{f}_{\mathrm{r}} \pm \mathrm{kf} \mathrm{f}_{\mathrm{i}}$

Ball defect: $\quad \mathrm{f}_{\text {ecc }}=\mathrm{f}_{\mathrm{s}} \pm \mathrm{f}_{\text {cage }} \pm \mathrm{kf}_{\mathrm{b}}$

Where $\mathrm{k}=1,2,3 \ldots$

This determination for air gap length by concerning time $t$ and angle for the stator frame reference. The radial rotor movement shown in figure 4 and length will be varied as a function to determine the defect [30]. This defect is making a hole artificially in the rotor surface of the bearing element.

\section{RESULTS \& DISCUSSION}

While simulating the broken bar fault, a rotor with 29 bars is considered. Each bar is treated separately and is expressed in terms of its equivalent circuit, which consists of resistance and inductance. First, a healthy motor was considered and its stator current spectrum and rotor angular speed were plotted in a MATLAB environment. Figure 5 shows the simple data acquisition system.

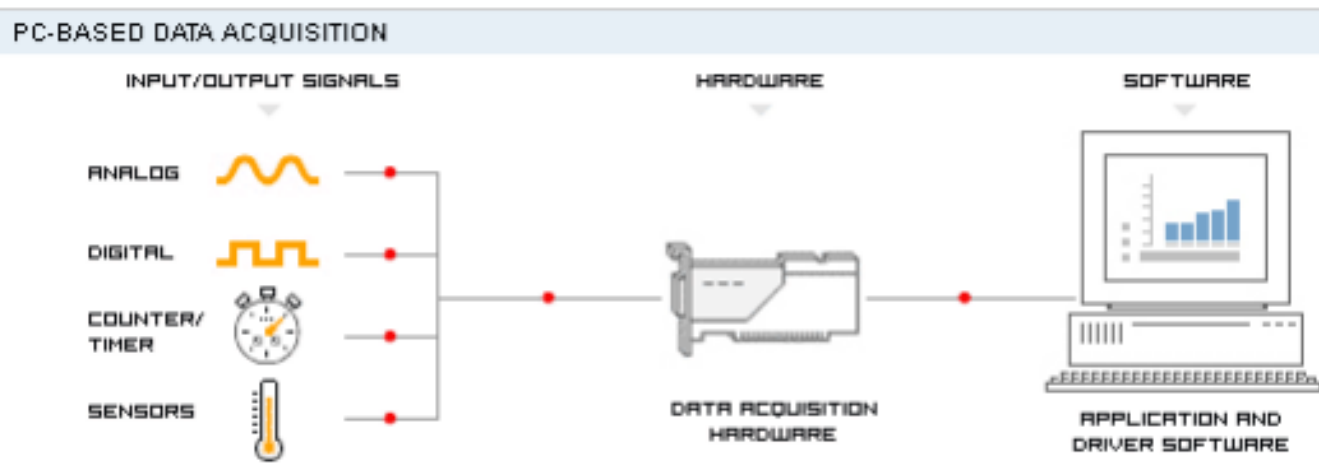

Figure 5 Data Acquisition System

ISSN: 2582-4252 (online)

60

Submitted: 02.03.2021

Revised: 16.03.2021

Accepted: 27.03.2021

Published: 12.04.2021 
Journal of Innovative Image Processing (JIIP) (2021)

Vol.03/ No. 01

Pages: 52-65

https://www.irojournals.com/iroiip/

DOI: https://doi.org/10.36548/jiip.2021.1.005

It is shown in Figures 6, 7, 8, and 9 that, the stator current spectrum has only one significant magnitude at the fundamental frequency, and the rotor speed curve increases initially and reaches a stable value after which it remains constant. The spectrum shows one significant value at the fundamental frequency. The spectrum of stator current and speed for a rotor with one broken rotor are shown below.
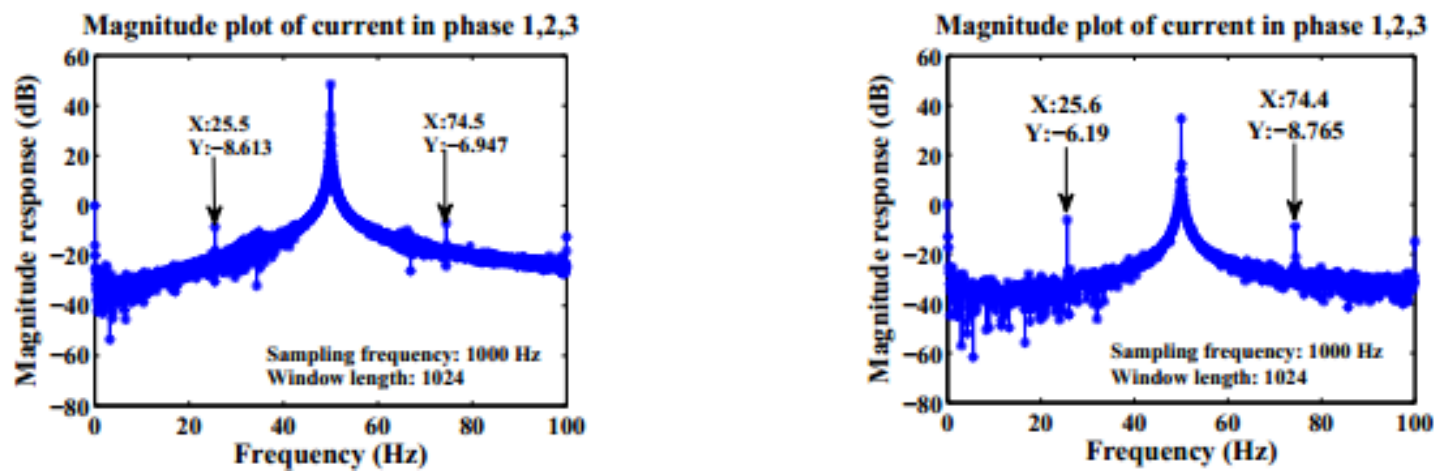

Figure 6 current spectrum of healthy motor Figure 7 current spectrum for stator Inter-turn fault

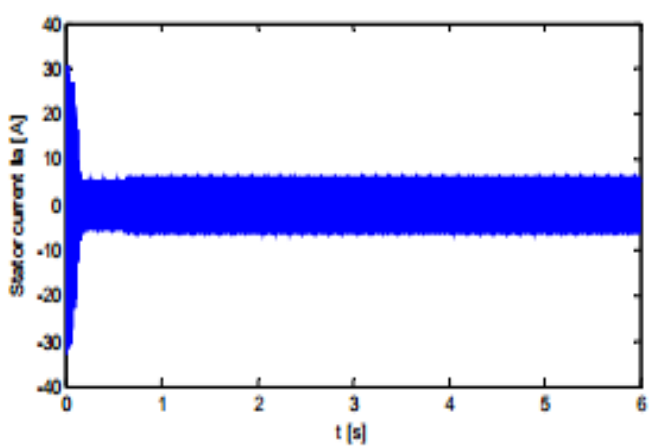

Figure 8 stator current for healthy motor

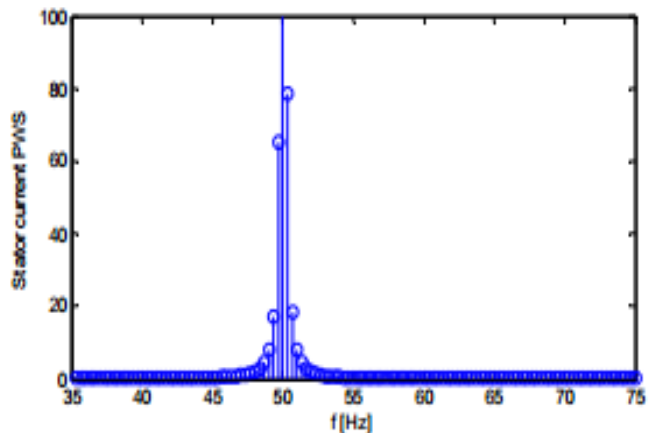

Figure 9 stator current spectrum

To create a broken bar fault, it is required to know the effect of breaking a bar. If the rotor bar is broken, its resistance (R_rr), inductance (L_rr), and mutual inductance (L_sr) will be changed. In fact the changes in inductances are negligible compared to resistance change. The laminated rotor gets current flow from the core of the coil. In the proposed model, the fault has been created by making the broken rotor bar resistance $10^{4}$ times the resistance of a healthy motor. 
Journal of Innovative Image Processing (JIIP) (2021)

Vol.03/ No. 01

Pages: 52-65

https://www.irojournals.com/iroiip/

DOI: https://doi.org/10.36548/jiip.2021.1.005

\section{CONCLUSION}

Since, fault detection and diagnosis of induction motor is still a challenging task for researchers and academicians, the proposed research work has attempted to summarize recent developments and design of fine-tuned factor for vibration frequency method in an induction motor for performing fault diagnostics and prognostics. Proposed vibration-based techniques, models, and algorithms have been analyzed and a particular suitable technique is developed for a specific fault diagnosis. The main aim of our research article is to diagnose the electrical and mechanical faults with the help of suitable signal processing techniques. The proposed research article deals with:

1. Designing Fine-tuned vibration frequencies technique for condition monitoring and fault detection method.

2. LabVIEW software and data acquisition system (DAQ card) are the advanced technologies used to accurately express the frequency spectrum of the healthy condition of induction motor and helps to distinguish the faulty spectrum by comparing two specified frequencies. But due to the high cost of DAQ card hardware, LabVIEW software is not implemented practically in the proposed research work.

3. The occurrence of different faults in an induction motor are diagnosed using MATLAB SIMULINK.

The vibration signal processing technique is sensitive towards various components and factors like vibration arise from the unfixed base of the induction motor and different casing problems of the induction motor. The wavelet or Fourier transform methods are required to obtain highly efficient robust control to identify faults in an induction motor.

\section{REFERENCES}

[1] Refaat, S.S., Abu-Rub, H., Saad, M.S., Aboul-Zahab, E.M., Iqbal, A., "Detection, diagnoses and discrimination of stator turn-to-turn fault and unbalanced supply voltage fault for threephase induction motors," Power and Energy (PECon), 2012 IEEE International Conference on 25 Dec. 2012, pp.910-915.

ISSN: 2582-4252 (online) 
Journal of Innovative Image Processing (JIIP) (2021)

Vol.03/ No. 01

Pages: 52-65

https://www.irojournals.com/iroiip/

DOI: https://doi.org/10.36548/jiip.2021.1.005

[2] Mehala, Neelam, and Ratna Dahiya. "Motor current signature analysis and its applications in induction motor fault diagnosis." International journal of systems applications, engineering \& development vol.2, no. 1, pp.29-35, 2007.

[3] Dash, Sourabh, and Venkat Venkatasubramanian. "Challenges in the industrial applications of fault diagnostic systems." Computers \& Chemical Engineering, 24.2 (2000): pp. 785-791. [4] M. Kathiravan and K. Prakasam, "Motor current signature analysis based Fault diagnosis of induction motor", International Journal of Power Control and Computation(IJPCSC), vol. 6, no. 2, pp. 56-62, Jan-March 2014.

[5] Ielyzaveta Chernyavskal and OndĜej Vítek, "Analysis of Broken Rotor Bar Fault in a SquirrelCage Induction Motor by Means of Stator Current and Stray Flux Measurement", International Power Electronics and Motion Control Conference, 24 November 2016.

[6] T. C H. Anil, Kumar, Gurmeet Singh and V. N. A. Naikan, "Effectiveness of Vibration and Current Monitoring in detecting Broken Rotor Bar and Bearing Faults in an Induction Motor", International Conference on Power Systems, 06 October 2016.

[7] A Singhal and M A. Khandekar, "Bearing Fault Detection in Induction Motor Using Motor Current Signature Analysis", International Journal of Advanced Research in Electrical Electronics and Instrumentation Engineering, vol. 2, no. 7, pp. 3258-3264, July 2013.

[8] Matta Suresh and K.C. Deekshit Kompella, "Diagnosis of Induction Motor Stator Faults by using Motor Current Signature Analysis Method", IJCT A, vol. 10, no. 5, pp. 541-550, 2017.

[9] Ielyzaveta Ishkova and Ondřej Vítek, "Diagnosis of eccentricity and broken rotor bar related faults of induction motor by means of motor current signature analysis", International Scientific Conference on Electric Power Engineering, 2015.

[10] Pravin P. Joshi and M.R. Bachwad, "Condition Monitoring of Induction Motor with A Case Study", International Journal of Electrical Engineering \& Technology (IJEET), vol. 6, no. 6, pp. 10-15, June 2015.

[11] Kato, T., Inoue, K., Yoshida, K., Itokawa, T., "Diagnosis of multi-turn faults of induction motor by direct detection of asymmetry admittance component," Power Electronics and Drive Systems (PEDS), 2013 IEEE 10th International Conference on 22-25 April 2013, pp.778783.

ISSN: 2582-4252 (online) 
Journal of Innovative Image Processing (JIIP) (2021)

Vol.03/ No. 01

Pages: 52-65

https://www.irojournals.com/iroiip/

DOI: https://doi.org/10.36548/jiip.2021.1.005

[12] Trabelsi, M., M. Boussak, P. Mestre, and M. Gossa. "Pole voltage based approach for IGBTs open circuit fault detection and diagnosis in PWM-VSI-Fed induction motor drives." In Power Engineering, Energy and Electrical Drives (POWERENG), 2011 International Conference on, pp. 1-6. IEEE, 2011.

[13] Aktas, M., Turkmenoglu, V., "Wavelet-based switching faults detection in direct torque control induction motor drives," Science, Measurement \& Technology, IET vol.4, no.6, pp.303310, November 2010.

[14] Das, S., Purkait, P., Chakravorti, S., "Separating Induction Motor Current Signature for stator winding faults from that due to supply voltage unbalances," Power and Energy in NERIST (ICPEN), 2012 1st International Conference on, vol., no., pp. 1-6, 28-29 Dec. 2012.

[15] Khan, M., Rahman, M.A., "Discrete Wavelet Transform Based Detection of Disturbances in Induction Motors," Electrical and Computer Engineering, 2006; International Conference on 19-21 Dec. 2006, pp.462-465.

[16] Soualhi, Abdenour, Guy Clerc, and Hubert Razik. "Detection and diagnosis of faults in induction motor using an improved artificial ant clustering technique."Industrial Electronics, IEEE Transactions on 60, no. 9 (2013): 4053-4062.

[17] Amaral, T.G., Pires, V.Fernao, Martins, J.F., Pires, A.J., Crisostomo, Manuel M., "Statistic Moment Based Method for the Detection and Diagnosis of Induction Motor Stator Fault," Power Engineering, Energy and Electrical Drives, 2007. POWERENG 2007. International Conference on, 12-14 April 2007, pp.106-110.

[18] Eltabach, M., Charara, A., Antoni, J., "Comparative investigation of non-invasive diagnosis methods for mechanical fault detection in induction motors," Industrial Electronics, 2004 IEEE International Symposium on, 4-7 May 2004, vol.1, pp.365-370.

[19] Chetwani, S. H., M. K. Shah, and M. Ramamoorty. "On-line condition monitoring of induction motors through signal processing." In Electrical Machines and Systems, 2005. ICEMS 2005. Proceedings of the Eighth International Conference on, vol. 3, pp. 2175-2179. IEEE, 2005.

[20] Sousa, K.M.; Dreyer, U.J.; Martelli, C.; Da Silva, J.C.C. Dynamic Eccentricity Induced in Induction Motor Detected by Optical Fiber Bragg Grating Strain Sensors. IEEE Sens. J. 2016, 16, 4786-4792. [CrossRef]

ISSN: 2582-4252 (online) 
Journal of Innovative Image Processing (JIIP) (2021)

Vol.03/ No. 01

Pages: 52-65

https://www.irojournals.com/iroiip/

DOI: https://doi.org/10.36548/jiip.2021.1.005

[21] Kang, T.-J.; Kim, J.; Bin Lee, S.; Yung, C. Experimental Evaluation of Low-Voltage Offline Testing for Induction Motor Rotor Fault Diagnostics. IEEE Trans. Ind. Appl. 2015, 51, 13751384. [CrossRef]

[22] Godoy, W.F.; Da Silva, I.N.; Lopes, T.D.; Goedtel, A.; Palácios, R.H.C. Application of intelligent tools to detect and classify broken rotor bars in three-phase induction motors fed by an inverter. IET Electr. Appl. 2016, 10, 430-439. [CrossRef]

[23] Frosini, L.; Harlisca, C.; Szabó, L. Induction Machine Bearing Fault Detection by Means of Statistical Processing of the Stray Flux Measurement. IEEE Trans. Ind. Electron. 2015, 62, 18461854. [CrossRef]

[24] Faiz, J.; Nejadi-Koti, H.; Valipour, Z. Comprehensive review on inter-turn fault indexes in permanent magnet motors. IET Electr. Appl. 2017, 11, 142-156. [CrossRef]

[25] Abdallah, H.; Benatman, K. Stator winding inter-turn short-circuit detection in induction motors by parameter identification. IET Electr. Appl. 2017, 11, 272-288. [CrossRef]

[26] Ghanbari, T. Autocorrelation function-based technique for stator turn-fault detection of induction motor. IET Sci. Meas. Technol. 2016, 10, 100-110. [CrossRef]

[27] Maitre, J.; Bouchard, B.; Bouzouane, A.; Gaboury, S. Classification Algorithms Comparison for Interturn Short-Circuit Recognition in Induction Machines Using Best-Fit 3-D-Ellipse Method. Can. J. Electr. Comput. Eng. 2017, 40, 255-265.

[28] Hou, Z.; Huang, J.; Liu, H.; Ye, M.; Liu, Z.; Yang, J. Diagnosis of broken rotor bar fault in open- and closed-loop controlled wye-connected induction motors using zero-sequence voltage. IET Electr. Power Appl. 2017, 11, 1214-1223. [CrossRef]

[29] Boudinar, A.H.; Benouzza, N.; Bendiabdellah, A. Induction Motor Bearing Fault Analysis Using a Root-MUSIC Method. IEEE Trans. Ind. Appl. 2016, 52, 3851-3860. [CrossRef]

[30] Antonino-Daviu, J.A.; Arkkio, A.; Georgoulas, G.; Climente-Alarcon, V.; Tsoumas, I.P.; Stylios, C.D.; Nikolakopoulos, G. The Use of a Multilabel Classification Framework for the Detection of Broken Bars and Mixed Eccentricity Faults Based on the Start-Up Transient. IEEE Trans. Ind. Inform. 2017, 13, 625-634.

ISSN: 2582-4252 (online) 